\title{
Informal Care Time and Cost in a Large Clinical Trial Sample of Patients with Mild to Moderate Alzheimer's Disease: Determinants and Level of Change Observed
}

Loretto Lacey $\cdot$ Joel Bobula $\cdot$ Timothy Niecko $\cdot$ Christopher Leibman

Received: May 4, 2016/ Published online: November 22, 2016

(C) The Author(s) 2016. This article is published with open access at Springerlink.com

\section{ABSTRACT}

Introduction: We evaluate the association between caregiver (informal) time/cost and illness severity from two recently completed clinical trials of an investigational drug for Alzheimer's disease (AD).

Methods: Changes from baseline caregiver time were calculated and treatment effects analyzed using a restricted maximum likelihood-based mixed model for repeated measures. Four separate models were then estimated to examine the association between caregiver time costs and the clinical endpoints measured

Enhanced content To view enhanced content for this article go to http://www.medengine.com/Redeem/ 9227F060136E97EF.

L. Lacey

Lacey Solutions, Ltd., The Beaches, South Strand,

Skerries, Dublin, Ireland

J. Bobula $(\bowtie)$

Pfizer Inc., 500 Arcola Road, Collegeville, PA 19426, USA

e-mail: joel.bobula@pfizer.com

T. Niecko

Niecko Health Economics, LLC, 275 Indies Way,

Naples, FL 34110, USA

C. Leibman

Biogen, Zählerweg 6, 6300 Zug, Switzerland during the trials, including cognition (MMSE), function (DAD), behavior (NPI), global disability (CDR) and dependence (DS).

Results: Caregiver time cost was significantly associated with all clinical measures of illness severity with a 1-unit change in MMSE, DAD, NPI, CDR and DS associated with a $11.57 \%$, $4.81-4.97 \%, 3.58-3.67 \%, 42.52 \%$ and $71.05 \%$ change, respectively, in primary caregiver time cost. The association between caregiver time cost and DS was the strongest of all the associations examined.

Conclusion: Caregiver time costs increase with increasing $\mathrm{AD}$ severity in all key domains of $\mathrm{AD}$ (cognition, function, behavior, global disability and dependence on others). Our analysis demonstrated that patient dependence is a particularly important predictor of caregiver time costs and should be considered as a potential outcome measure in intervention clinical trials in AD.

Funding: Pfizer Inc. and Janssen Alzheimer Immunotherapy Research and Development.

Keywords: Alzheimer's disease; Informal caregiver; Time and costs 


\section{INTRODUCTION}

Alzheimer's disease is a progressive dementia characterized by cognitive deficits, altered behavior and inability to care for oneself. Sixty to seventy percent of persons with $\mathrm{AD}$ live in the community, with much of the care provided by family or other unpaid persons [1]. These unpaid caregivers provide an estimated 17.4 billion hours of unpaid care per year, constituting an estimated value of $\$ 210$ billion [1]. The value placed on caregiver time, informal care cost, represents the largest component of the total cost of care for $\mathrm{AD}$ [2-7]. Estimates range from $37 \%$ of total care costs in community dwelling patients participating in a study in Scandinavia [3] to $86 \%$ of the total cost of care in a clinical trial sample of mild to moderate $\mathrm{AD}$ from multiple countries [4]. A study of cost of illness in dementia reported that $56 \%$ of total costs in the EU27 in 2008 were contributed by informal care costs [2]. In the US, Zhu et al. reported that when patients with $\mathrm{AD}$ are not institutionalized, informal care-giving cost represents $70 \%$ of the total cost of care [7].

Given the important role of care-giving time in the management of person with $\mathrm{AD}$, informal care time/cost has been included as an outcome measure in evaluations of $\mathrm{AD}$ treatments [8-12]. Some of these studies reported significant reductions in caregiver time with galantamine [8] and donepezil treatment in patients with $\mathrm{AD}$ [8-11] and others did not [12]. More recently, care-giving time was included as an outcome measure in two RCTs examining the efficacy of bapineuzumab in mild to moderate $\mathrm{AD}$, and is the focus of this analysis [13].

In the economic evaluation of interventions in $\mathrm{AD}$, it is frequently necessary to model the economic implications of changes in clinical progression (e.g., MMSE), in order to determine cost-effectiveness. Having robust estimates of the associations between clinical progression measures and economic outcomes, like informal caregiver time, is very important for such models. Many studies have reported a significant association between informal care-time (and -cost) and disease severity measures of cognition [3-5], function [4, 5, 14] and behavior [4, 5]. In Mauskopf et al.'s review of the literature, they concluded that functional and behavioral measures were consistently associated with caregiver time [15]. Two recent studies conducted comprehensive evaluations of associations in $\mathrm{AD}[4,5]$. Gustavsson et al. [4] examined the association between informal care and measures of cognition (MMSE, ADAS-COG), function (ADCS-AD), behavior (NPI-total and NPI distress) and global disability (CDR-SOB) using correlations. Whilst the authors provided estimates of the proportional change in total care cost with marginal change in clinical severity measures, no estimates were provided specifically for informal care cost. Rapp et al. [5] provided estimates of the proportional changes in informal care costs with marginal changes in MMSE, ADL, NPI and ZBI but did not examine associations with a global measure, like CDR-SOB and the dependence scale (DS). The large dataset from the two bapineuzumab randomized clinical trials (RCTs) provide a rich dataset to investigate associations between: (1) caregiver time and baseline severity and (2) informal care costs and baseline clinical severity measures, which are the aims of this current study.

\section{METHODS}

\section{Study Design}

Data from two 18 month, multi-center, randomized, double-blind, placebo 
controlled, parallel group trials examining bapineuzumab in patients with mild to moderate $\mathrm{AD}$ were merged in order to study caregiver time patterns in AD. The two studies had the same design: study ELN115727-301 (301) enrolled subjects with mild to moderate Alzheimer's disease (AD) who were apolipoprotein E $\varepsilon 4$ ( $\left.A P O E^{\star} E 4\right)$ non-carriers, and they were randomly assigned to receive bapineuzumab $(0.5$ and $1.0 \mathrm{mg} / \mathrm{kg}$ ) or placebo every 13 weeks for a total of six infusions. Study ELN115727-302 (302) enrolled similar subjects who were $A P O E^{\star} E 4$ carriers who were randomized to receive either bapineuzumab $(0.5-\mathrm{mg} / \mathrm{kg})$ or placebo by IV infusion. The studies recruited subjects in sites in the US. Informed consent was obtained from all participants, or, if not capable of providing informed consent, from their legally acceptable representative. The studies were conducted according to the Declaration of Helsinki and were approved by the Independent review board at each participating site.

Subjects were enrolled in the study if they were 50 to $<89$ years of age; had a diagnosis of probable $\mathrm{AD}$ according to the National Institute of Neurological and Communicative Disorders and Stroke/Alzheimer's Disease and Related Disorders Association (NINCDS/ ADRDA) criteria and a screening visit brain MRI scan consistent with a diagnosis of $\mathrm{AD}$; an MMSE score of 16-26 inclusive; a Rosen Modified Hachinski Ischemic score $\leq 4$ [16]; lived at home or independently in a community dwelling and had a caregiver who consented to participate in the study, could accompany the subject on all clinic visits, and was a reliable informant in the opinion of the Investigator. Subjects were excluded if they had clinically significant neurological disease other than $\mathrm{AD}$; a major psychiatric disorder; history of stroke or seizures; a brain MRI scan indicative of significant non-AD abnormality; or history or evidence of any clinically significant autoimmune disease or chronic illness, which was likely to result in deterioration affecting the subject's safety during the study.

The resource utilization of each patient was assessed using the RUD-Lite [17], which was administered at baseline, week 26, week 52, and week 78. A brief summary of total costs by cost category (direct medical, direct nonmedical and informal costs) is presented first. Since informal costs are the largest category of costs, this paper provides additional analysis on the caregiver time component of the RUD-Lite. Caregiver time was assessed for both primary and secondary caregivers over the past month and was calculated as the product of the average time spent caring per day by the number of days in a month spent caring. The primary caregiver total time was calculated as the sum of caregiver time allocated to instrumental activities of daily living (IADL), activities of daily living (ADL) and to supervision. The secondary caregiver total time was calculated in the same way. The total caregiver total time is the sum of the primary caregiver time and the secondary caregiver time, measured as hours per month. For the purposes of assigning costs, the number of caregiver hours was capped at $16 \mathrm{~h}$ per day to allow for $8 \mathrm{~h}$ of sleep per night, which is consistent with the approach taken by other researchers [18]. Caregiver time was costed by assigning $30 \%$ of the average hourly wage of $\$ 23.54$ (\$7.06) to account for lost leisure time and not full hourly wage. In the literature, others have assigned $25-35 \%$ of the average hourly wage to caregiver time to account for lost leisure time [19-21]. 
At each visit, cognitive function was assessed using the Alzheimer's Disease Assessment Scale-Cognitive Subscale (ADAS-Cog; range 0-70) [22] and Mini Mental State Examination (MMSE; 0-30) [23], functional ability with the disability assessment for dementia (DAD; range 0-100\%) [24] and neuropsychiatric symptoms with the neuropsychiatric Inventory (NPI; range 0-144) [25]. Patient dependence on others was assessed using the dependence scale (DS; range 0-15) [26]. Global disability was assessed using the clinical dementia rating scale (CDR) [27]. In addition, the age and gender of patients and caregivers, their relationship, and marital status was recorded.

\section{Analysis}

\section{Total Cost Analysis Using Merged 301 and 302}

\section{Dataset}

The resource use and estimated costs at each visit corresponded to the 6-month period preceding the visit (i.e. -26 to $0,1-26,27-52$, and 53-78 weeks). Unit costs (\$US inflated to 2012) were applied to the resource use data collected in the study. Table 1 provides details of the component costs contributing to total costs and the sources used.

\section{Informal Caregiver Time Analysis Using Merged 301 and 302 Dataset}

The mean changes in primary caregiver and secondary caregiver time at week 78 were determined for three sub-groups of patients with the following baseline severity: (1) very mild (MMSE $\geq 24$ ); (2) mild (MMSE $\geq 21$ ); (3) moderate (MMSE $<21$ ).

To understand the relative distribution of time across different caring tasks, the mean times primary caregivers allocated to IADLs, ADLs and supervision at baseline and week 78 were estimated using the merged dataset.
Informal Care Cost Analysis Using Merged 301 and 302 Dataset

Using generalized linear modelling (GLM), the association between caregiver time cost over the previous 6 months and baseline clinical measures of severity was estimated. Caregiver time costs were log transformed to improve normality. Four models were investigated: the first examined associations with cognition (MMSE), function (DAD) and behavior (NPI); the second with an alternative measure of cognition (ADAS-COG), as well as function (DAD) and behavior (NPI); the third with a global measure (CDR-SOB) and the fourth with an alternative global measure (DS). All models controlled for patient age and gender.

\section{RESULTS}

\section{Caregiver and Patient Demography and Characteristics}

Baseline patient demographics are presented in Table 2 and caregiver demographics in Table 3. A total of 2204 patients participated in the 301 and 302 studies and were randomized to receive either placebo (925) or bapineuzumab (1279). The two groups in each study were similar at baseline with respect to patient age, gender, duration of $\mathrm{AD}$ and severity of $\mathrm{AD}$, as measured by the MMSE. The mean for the total population of 21.0 for MMSE is consistent with the Mild to Moderate AD entry criteria. The two groups in each study were similar with respect to caregiver characteristics. Approximately 90\%, overall, lived with the patient (Table 3). Approximately $75 \%$ of primary caregivers reported that there were no other caregivers (Table 3).

In comparison with other recent survey data on caregivers of Alzheimer's patients 
Table 1 SUS unit costs assigned to resource use components of Rud-lite

Accommodation

Intermediate forms of accommodation (not dementia-specific) (per day) ${ }^{\mathrm{a}}$

$\$ 116.71$

Dementia-specific residential accommodation (per day) ${ }^{\mathrm{a}}$

$\$ 158.04$

Long-term institutional care/nursing home -private room (per day) ${ }^{a}$

$\$ 261.00$

Community services

Registered nurse home visits (per visit) ${ }^{\mathrm{b}, \mathrm{h}}$

$\$ 139.08$

Home health aide/orderly (per hour) ${ }^{\mathrm{a}}$

Food delivery/Meals on wheels (per meal) ${ }^{c}$

Day care (per day) ${ }^{\mathrm{a}}$

Transportation (publicly/insurance paid) (round trip) ${ }^{a}$

Inpatient care

Geriatric (per night) $)^{\text {d,h }}$

Psychiatric (per night) $)^{\mathrm{d}, \mathrm{h}}$

Internal Medicine (per night) ${ }^{\mathrm{d}, \mathrm{h}}$

$\$ 7220.37$

Surgery (per night) $)^{\mathrm{d}, \mathrm{h}}$

Other (per night) $)^{\mathrm{d}, \mathrm{h}}$

ER (per visit) ${ }^{\mathrm{e}, \mathrm{h}}$

Outpatient care

General practitioner (per visit) ${ }^{\mathrm{f}, \mathrm{h}}$

Geriatrician (per visit) ${ }^{\mathrm{f}, \mathrm{h}}$

Neurologist (per visit) f,h $^{\mathrm{f}}$

$\$ 148.13$

Psychiatrist (per visit) ${ }^{\mathrm{f}, \mathrm{h}}$

Physiotherapist (per visit) f,h $^{\mathrm{f}}$

Occupational therapist (per visit) ${ }^{\mathrm{f}, \mathrm{h}}$

Social worker (per visit) ${ }^{\mathrm{f}, \mathrm{h}}$

Psychologist (per visit) ${ }^{\mathrm{f}, \mathrm{h}}$

Other (specialist, please specify) (per visit) ${ }^{\mathrm{f}, \mathrm{h}}$

$\$ 148.13$

Caregiving time

Caregiver informal care time (per hour) $)^{\mathrm{g}}$

$\$ 7.06$

a Metlife Mature Market Institute-Market Survey of Long-Term Care Costs (Nov 2012)

b CPT code 99349, page 83 of 2008 PF\&CG (inflated to 2012 dollars)

c http://www.sdslane.org/mow.html

d HCUP All cause hospitalization discharges, 2010 (inflated to 2012 dollars)

e HCUP Emergency Department State Statistics, 2005 (inflated to 2012 dollars)

f CPT code 99243, page 69 of 2008 PF\&CG (inflated to 2012 dollars)

g Employment, hours, and earnings from the current employment statistics survey (National)

$\mathrm{h}$ Medical care inflation index

[1], caregivers in the 301 and 302 studies tended to be older on average (65 versus 52 years of age), less likely to be female $(60 \%$ versus $70 \%$ female), and more likely to be the spouse of the subject $(70 \%$ versus 6-17\%). 
Table 2 Patient demographics and baseline characteristics

\begin{tabular}{|c|c|c|c|c|c|}
\hline & \multicolumn{2}{|l|}{301} & \multicolumn{2}{|l|}{302} & \multirow{2}{*}{$\begin{array}{l}\text { Merged } 301+302 \\
\text { Total } \\
(N=2204)\end{array}$} \\
\hline & $\begin{array}{l}\text { Placebo } \\
(N=493)\end{array}$ & $\begin{array}{l}\text { Bapineuzumab } \\
\text { (pooled) } \\
(N=621)\end{array}$ & $\begin{array}{l}\text { Placebo } \\
(N=432)\end{array}$ & $\begin{array}{l}\text { Bapineuzumab } \\
(0.5 \mathrm{mg} / \mathrm{kg}) \\
(N=658)\end{array}$ & \\
\hline \multicolumn{6}{|l|}{ Age (years) } \\
\hline$N$ & 493 & 621 & 432 & 658 & 2204 \\
\hline Mean (SD) & $71.9(10.10)$ & $73.1(9.35)$ & $72.3(8.40)$ & $72.0(8.03)$ & $72.4(8.94)$ \\
\hline \multicolumn{6}{|c|}{ Gender, $n(\%)$} \\
\hline Male & $245(49.7)$ & $281(45.2)$ & $190(44.0)$ & $300(45.6)$ & $1016(46.1)$ \\
\hline Female & $248(50.3)$ & $340(54.8)$ & $242(56.0)$ & $358(54.4)$ & $1188(53.9)$ \\
\hline \multicolumn{6}{|c|}{ Duration of AD (years) } \\
\hline$N$ & 493 & 621 & 432 & 658 & 2204 \\
\hline Mean (SD) & $3.1(2.32)$ & $3.1(2.43)$ & $3.5(2.48)$ & $3.4(2.37)$ & $3.2(2.40)$ \\
\hline \multicolumn{6}{|l|}{ MMSE } \\
\hline$N$ & 493 & 621 & 452 & 658 & 2204 \\
\hline Mean (SD) & $21.2(3.21)$ & $21.2(3.31)$ & $20.7(3.17)$ & $20.8(3.15)$ & $21.0(3.22)$ \\
\hline \multicolumn{6}{|l|}{ ADAS-COG } \\
\hline$N$ & 493 & 621 & 432 & 658 & 2204 \\
\hline Mean (SD) & $22.2(10.08)$ & $22.3(9.85)$ & $23.9(9.52)$ & $23.5(9.44)$ & $22.9(9.74)$ \\
\hline \multicolumn{6}{|l|}{$\mathrm{DAD}$} \\
\hline$N$ & 493 & 621 & 432 & 658 & 2204 \\
\hline Mean (SD) & $80.5(19.5)$ & $80.2(18.46)$ & $79.4(18.85)$ & $80.9(17.32)$ & $80.3(18.36)$ \\
\hline \multicolumn{6}{|l|}{ NPI } \\
\hline$N$ & 479 & 603 & 423 & 642 & 2147 \\
\hline Mean (SD) & $11.2(12.42)$ & $11.0(12.60)$ & $10.1(11.75)$ & $10.0(11.85)$ & $10.6(12.18)$ \\
\hline \multicolumn{6}{|l|}{ DS } \\
\hline$N$ & 493 & 619 & 431 & 658 & \\
\hline Mean (SD) & $4.6(2.23)$ & $4.6(2.29)$ & $4.8(2.0)$ & $4.7(2.07)$ & $4.7(2.16)$ \\
\hline
\end{tabular}

\section{Total Cost Analysis Using Merged 301} and 302 Dataset

Based on the merged dataset, the mean total and component costs of care are presented for each visit in Fig. 1. The mean total cost of care for the previous 6 months was estimated to be US \$9144 at baseline and US\$17,066 at week 78. The total cost of care includes informal care costs (based on caregiver time) and the cost of healthcare (direct medical cost) and social care services used (direct nonmedical costs). Direct 
Table 3 Caregiver demographics and characteristics at baseline

\begin{tabular}{|c|c|c|c|c|}
\hline & \multicolumn{2}{|l|}{301} & \multicolumn{2}{|l|}{302} \\
\hline & $\begin{array}{l}\text { Placebo } \\
(N=493)\end{array}$ & $\begin{array}{l}\text { Bapineuzumab } \\
\text { (pooled) }^{\mathrm{a}} \\
(N=621)\end{array}$ & $\begin{array}{l}\text { Placebo } \\
(N=432)\end{array}$ & $\begin{array}{l}\text { Bapineuzumab } \\
(0.5 \mathrm{mg} / \mathrm{kg}) \\
(N=658)\end{array}$ \\
\hline \multicolumn{5}{|l|}{ Age (years) } \\
\hline$N$ & 491 & 617 & 429 & 655 \\
\hline Mean (SD) & $64.9(13.28)$ & $64.0(13.75)$ & $65.4(12.30)$ & $65.5(12.07)$ \\
\hline \multicolumn{5}{|l|}{ Gender, $n(\%)$} \\
\hline Male & $181(36.7)$ & $243(39.2)$ & $185(42.9)$ & $281(42.8)$ \\
\hline Female & $312(63.3)$ & $377(60.8)$ & $246(57.1)$ & $375(57.2)$ \\
\hline Missing & 0 & 1 & 1 & 2 \\
\hline \multicolumn{5}{|c|}{ Relationship to subject, $n(\%)$} \\
\hline Husband & $141(28.6)$ & $182(29.4)$ & $152(35.3)$ & $236(36.0)$ \\
\hline Wife & $213(43.2)$ & $229(36.9)$ & $170(39.4)$ & $261(39.8)$ \\
\hline Child & $94(19.1)$ & $143(23.1)$ & $74(17.2)$ & $114(17.4)$ \\
\hline Friend & $13(2.6)$ & $19(3.1)$ & $10(2.3)$ & $19(2.9)$ \\
\hline Healthcare professional & $3(0.6)$ & $7(1.1)$ & $6(1.4)$ & $3(0.5)$ \\
\hline Other & $29(5.9)$ & $40(6.5)$ & $19(4.4)$ & $22(3.4)$ \\
\hline Missing & 0 & 1 & 1 & 3 \\
\hline \multicolumn{5}{|l|}{ Marital status, $n(\%)$} \\
\hline Married/cohabitating & $430(87.6)$ & $533(86.5)$ & $380(89.2)$ & $588(89.8)$ \\
\hline Never married & $25(5.1)$ & $37(6.0)$ & $12(2.8)$ & $27(4.1)$ \\
\hline Divorced/separated & $27(5.5)$ & $28(4.5)$ & $29(6.8)$ & $29(4.4)$ \\
\hline Widowed & $9(1.8)$ & $18(2.9)$ & $5(1.2)$ & $11(1.7)$ \\
\hline Missing & 2 & 5 & 6 & 3 \\
\hline \multicolumn{5}{|c|}{ Do you live with the subject? $n(\%)$} \\
\hline Yes & $406(88.8)$ & $235(82.7)$ & $359(93.5)$ & $544(94.9)$ \\
\hline No & $51(11.2)$ & $49(17.3)$ & $25(6.5)$ & $29(5.1)$ \\
\hline Missing & 36 & 23 & 48 & 85 \\
\hline \multicolumn{5}{|c|}{ How many additional caregivers? $n(\%)$} \\
\hline 0 & $367(74.9)$ & $442(71.4)$ & $325(75.6)$ & $476(72.7)$ \\
\hline 1 & $73(14.9)$ & $111(17.9)$ & $56(13.0)$ & $101(15.4)$ \\
\hline 2 & $28(5.7)$ & $38(6.1)$ & $27(6.3)$ & $38(5.4)$ \\
\hline 3 & $10(2.0)$ & $14(2.3)$ & $10(2.3)$ & $23(3.5)$ \\
\hline$\geq 4$ & $12(2.4)$ & $14(2.3)$ & $12(2.8)$ & $17(2.6)$ \\
\hline Missing & 3 & 2 & 2 & 3 \\
\hline
\end{tabular}

${ }^{a}$ Bapineuzumab 0.5 and $1.0 \mathrm{mg} / \mathrm{kg}$ pooled 


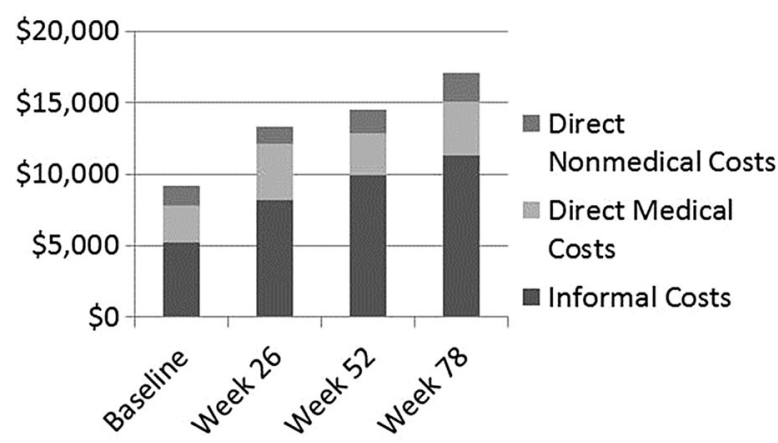

Fig. 1 Mean costs for previous 6 months from baseline to week 78

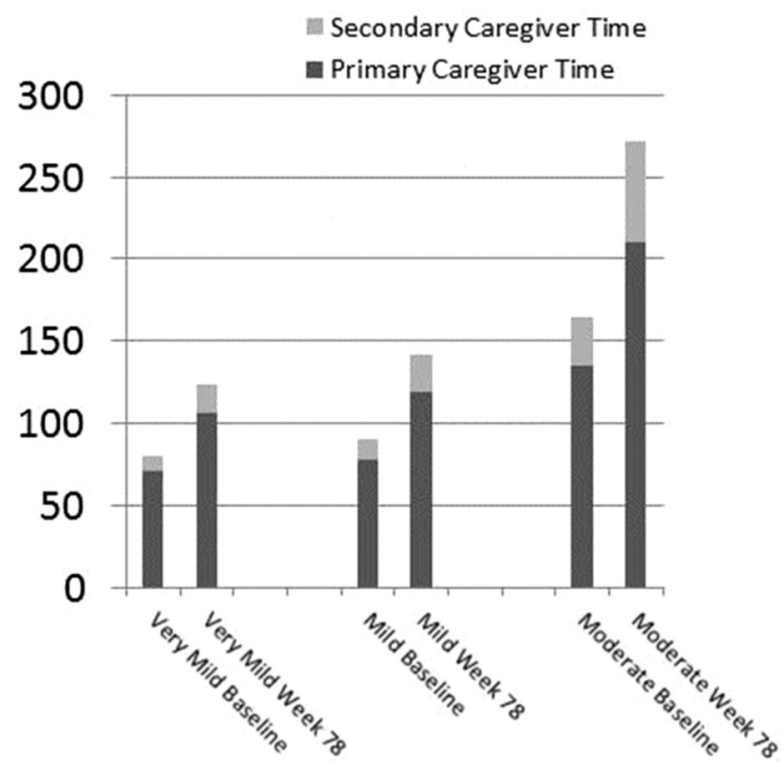

Fig. 2 Mean caregiver time (hours per month) by baseline severity, as measured by the MMSE

medical costs increased $45 \%$ over the 78 week period, from $\$ 2591$ at baseline to $\$ 3746$ at week 78. Direct nonmedical costs increased 54\%, from $\$ 1323$ at baseline to $\$ 2038$ at week 78 . Caregiver time increased $116 \%$, from $\$ 5230$ at baseline to $\$ 11,282$ at week 78 . Caregiver time represented the largest percentage of total care costs, at $57.2 \%$ at baseline and $66.1 \%$ at week 78. Other than caregiver time, the only component of total care costs to increase its percentage contribution to total care cost from

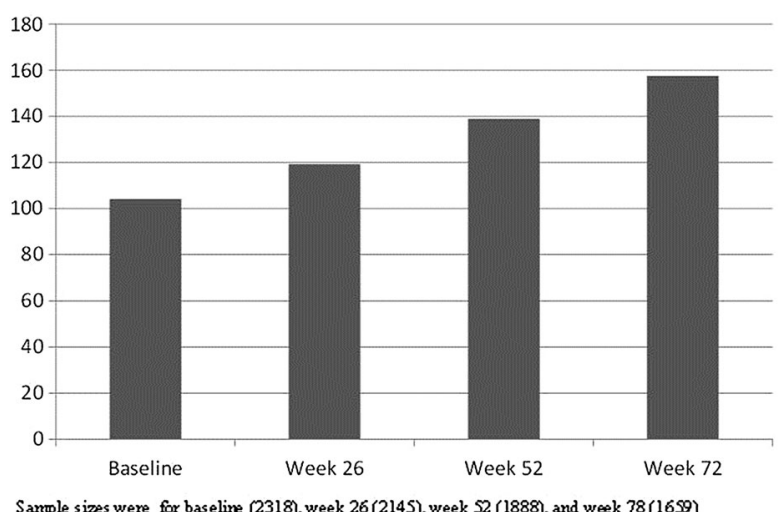

Fig. 3 Mean primary caregiver time (hours per month) over time using pooled dataset

baseline (4.5\%) to week 78 (7.1\%) was community care cost.

\section{Informal Caregiver Time Analysis Using Merged 301 and 302 Dataset}

The mean primary caregiver time and secondary caregiver time at baseline and week 78 are presented for three sub-groups of patients defined by their baseline MMSE into very mild, mild and moderate $\mathrm{AD}$ and for the total sample in Fig. 2. In general, both the baseline and week 78 mean caregiver time tended to increase with increasing severity of the sub-groups. In addition, the mean change in caregiver time at week 78 tended to increase with increasing severity.

The mean primary caregiver time over each time point is presented in Fig. 3. Primary caregiver time increased by approximately 15-20 h every 6 months.

The mean primary caregiver time allocated to IADLs, ADLs and supervision at baseline and week 78 is presented in Fig. 4. At baseline and week 78, primary caregiver time allocated to IADLs tended to be greater than time allocated to supervision, which tended to be greater than the time allocated to ADLs. An examination of 
Fig. 4 Mean primary caregiver time (hours per month) allocated to different tasks at baseline, week 78 and change at week 78 using pooled dataset

changes at week 78 suggests that total primary caregiver time increased considerably, particularly for supervision and ADLs.

\section{Associations Between Caregiver Time Costs and Clinical Severity}

The results of model estimates are presented in Table 4. The beta coefficient estimates the proportional change in the cost outcome for a unit change in the explanatory variable (e.g., MMSE). That is, for a 1-unit increase in the explanatory variable, cost increases by $100 \%$ beta. The models demonstrated significant associations between both log primary caregiver time and log total caregiver time cost over 6 months and clinical severity measures. Based on the beta coefficients for model 1, a 1-unit change in MMSE is associated with an $11.57 \%$ change in primary caregiver time cost and a $12.06 \%$ change in total caregiver time costs. Based on models 1 and 2, a 1-unit change in DAD is associated with a $4.81-4.97 \%$ change in primary caregiver time cost and $4.98-5.25 \%$ change in total caregiver time cost. Similarly, a 1 unit change in NPI is associated with a $3.58-3.67 \%$ increase in primary caregiver time cost and $3.85-3.97 \%$ increase in total caregiver

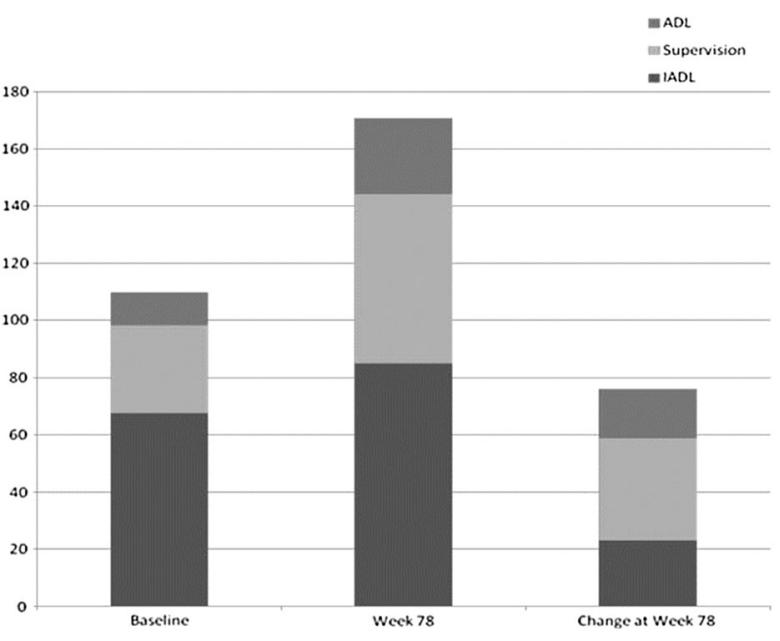

time cost. Model 3 suggests that a 1-unit change in CDR-SOB is associated with a $42.52 \%$ increase in primary caregiver time cost and $45.16 \%$ increase in total caregiver time cost. The higher $R^{2}$ for Model 4 suggests that association between DS and caregiver time cost is the strongest of all of the associations tested in Models 1-4. A 1-unit change in DS was associated with a $71.05 \%$ change in primary caregiver time cost and $73.67 \%$ increase in total caregiver time cost.

Patient age and gender were not significantly associated with either primary caregiver time costs or total caregiver time costs.

\section{DISCUSSION}

The lack of significant treatment differences in change in caregiver time at week 78 in the 301 and 302 study is consistent with the previously reported lack of clinical efficacy of bapineuzumab [17]. However, the large sample size $(2000+$ patients), longitudinal data (18 months), and data on a wide spectrum of clinical measures provided an opportunity to thoroughly investigate how caregiver time changes with patient severity and to quantify 


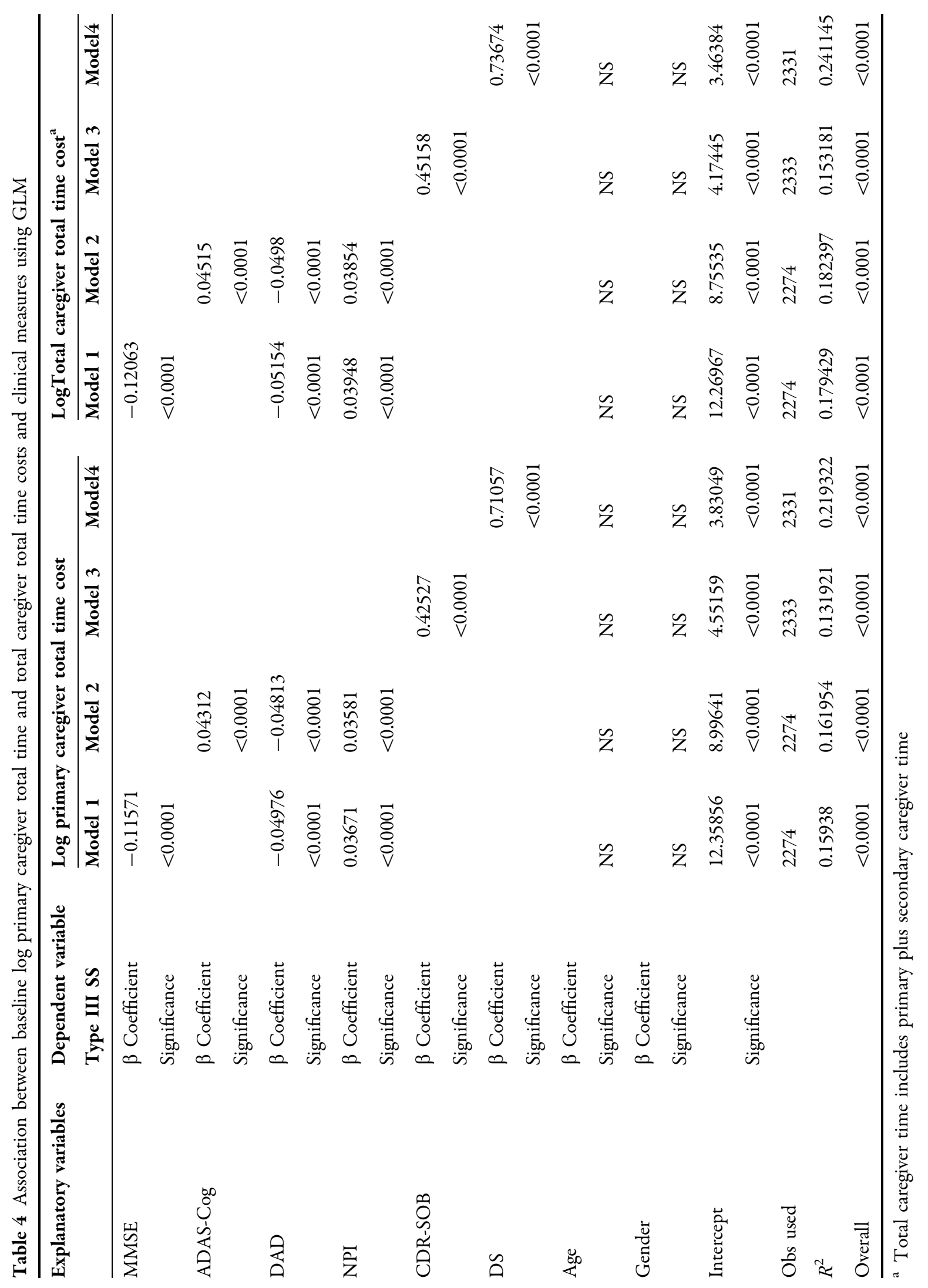


associations with a comprehensive set of clinical severity measures.

The trend towards increasing caregiver time with increasing cognitive decline, as measured by the MMSE, observed in our cross-sectional analysis, was consistent with previous reports [4]. The trend towards greater changes in caregiver time for the more severe sub-groups, was a new observation but still consistent with the above trend. The larger proportion of care-giving time dedicated to IADLs than supervision and ADLs at baseline in our sample is consistent with the functional and behavioral deficits experienced by patients with mild to moderate AD. Interestingly, the greatest changes over the 78 week period were related to supervision. Typically, in $\mathrm{AD}$, supervision is required to prevent wandering, falls, and other accidents.

The significant associations between clinical severity measures and informal care time are consistent with other reports $[3-5,15,16]$. The proportional change in primary caregiver (11\%) and total caregiver time cost (12\%) with a unit change in MMSE is higher than the 4.7 estimate reported by Rapp et al. [5]. The authors are unaware of any previous publications presenting the proportional change in informal care cost with unit change in DAD; it is not possible to compare our estimate of $4.97-5.15 \%$ change in informal care cost with marginal change in DAD. A comparison of $R$-squared for Models 1-4, suggests that the DS was the best predictor of informal care costs with the beta coefficient suggesting a $71-73 \%$ change in informal care cost with a one unit change in DS. Earlier studies have estimated that the DS worsens by 1 point per year [28].

The levels of change were much higher than that reported by Zhu et al. in their analysis of Predictor study dataset [29]. They reported that a one point increase in DS was associated with a
$\$ 1690$ increase in informal cost. As the baseline mean informal cost was $\$ 12,808$ in their study, the proportional change is considerably lower than our analysis showed. Our model differs from the Zhu model in that we did not include a functional measure as an additional explanatory variable in Model 4. Preliminary analysis suggested a strong correlation $(r=-0.630)$ between the DS and DAD, so we were concerned about multicollinearity effects.

There are a number of limitations associated with our analysis. Firstly, the sample is a clinical trial population, who must meet stringent inclusion and exclusion criteria, and so may not be representative of the general $\mathrm{AD}$ population.

Secondly, the RUD-Lite utilizes self-reported data by caregivers. Hence, the resource use data collection relies on accurate and consistent recall from caregivers estimating the health care resources used by the patient as well as the time that they spent, on a daily basis, caring for the patient. This element of the study may be subject to an element of bias, both from under- and over-estimations of resource use and time spent in caregiving.

Thirdly, there is considerable debate about how to assign costs to caregiver time. The approach taken can influence greatly the contribution of total cost of care attributed to care giving time [3]. We assigned $30 \%$ of the average hourly working rate.

Another limitation, highlighted by others [4] is the possible overestimation of time per day. For this reason we capped the daily care-giving time at $16 \mathrm{~h}$ for the purposes of costing informal care costs.

Whilst all of our four models were significant, the levels of variation in informal care cost explained ranged from $13 \%$ to $24 \%$ so there was a considerable amount of variation left unexplained. Other possible sources of variation could be co-morbidities, or 
ethnic/cultural differences, but these were not examined in this study.

\section{CONCLUSION}

Caregiver time costs increase with increasing $\mathrm{AD}$ severity in all key domains of AD (cognition, function, behavior, global disability, and dependence on others). Our analysis demonstrated that patient dependence is a particularly important predictor of caregiver time costs and should be considered as a potential outcome measure in intervention clinical trials in $\mathrm{AD}$.

\section{ACKNOWLEDGEMENTS}

Sponsorship and article processing charges for this study were funded by Pfizer Inc. and Janssen Alzheimer Immunotherapy Research and Development, LLC. All named authors meet the International Committee of Medical Journal Editors (ICMJE) criteria for authorship for this manuscript, take responsibility for the integrity of the work as a whole, and have given final approval for the version to be published. All authors had full access to all of the data in this study and take complete responsibility for the integrity of the data and accuracy of the data analysis.

Disclosures. Loretto Lacey was an employee of Janssen Alzheimer Immunotherapy Research and Development, LLC at the time the study was conducted. Christopher Leibman was an employee of Janssen Alzheimer Immunotherapy Research and Development, LLC at the time the study was conducted. Joel Bobula is an employee of Pfizer, Inc. Timothy Niecko was a paid contractor to Janssen Alzheimer Immunotherapy Research and Development, LLC, in the development of this manuscript.

\section{Compliance with Ethics}

Guidelines. Informed consent was obtained from all participants, or, if not capable of providing informed consent, from their legally acceptable representative. The studies were conducted according to the Declaration of Helsinki and were approved by the Independent review board at each participating site.

Data Availability. The datasets analyzed during the current study are not publicly available because they were collected under a partnership but the datasets may be available from the corresponding author on reasonable request pending review and approval from the Alliance.

Open Access. This article is distributed under the terms of the Creative Commons Attribution-NonCommercial 4.0 International License (http://creativecommons.org/licenses/ by-nc/4.0/), which permits any noncommercial use, distribution, and reproduction in any medium, provided you give appropriate credit to the original author(s) and the source, provide a link to the Creative Commons license, and indicate if changes were made.

\section{REFERENCES}

1. Alzheimer's Association. Alzheimer's disease facts and figures. 2012. http://www.alz.org/downloads/ facts_figures_2012.pdf. Accessed 8 May 2012.

2. Wimo A, Jonsson L, Gustavsson A, et al. The economic impact of dementia in Europe in 2008-cost estimates from the Eurocode project. Int J Geriatr Psychiatry. 2011;26:825-32.

3. Jonsson L, Eriksdotter Jonhagen M, Kilander L, Soininen H, Hallikainen M, Waldemar G, Nygaard $\mathrm{H}$, Andreasen N, Winblad B, Wimo A. Determinants of costs of care for patients with Alzheimer's disease. Int J Geriatr Psychiatry. 2006;21:449-59. 
4. Gustavsson A, Cattelin F, Jonsson L. Costs of care in a mild-moderate Alzheimer clinical trial sample: key resources and their determinants. Alzheimer's Dement. 2011;7:466-73.

5. Rapp T, Andrieu S, Molinier L, Grand A, Cantet C, Mullins D, Vellas B. Exploring the relationship between Alzheimer's disease severity and longitidinal costs. Value Health. 2012;15(3):412-9.

6. Gustavsson A, Jonsson L, Rapp T, et al. Differences in resource use and cost of dementia care between European countries: baseline data from the ICTUS study. JNHA. 2010;14(8):648-54.

7. Zhu CW, Sano M. Economic considerations in the management of Alzheimer's disease. Clin Interv Aging. 2006;1:143-54.

8. Wimo A, Winblad B, Shah S, et al. Impact of donepezil treatment for Alzheimer's disease on caregiver time. Curr Med Res Opin. 2004;20(8):1221-5.

9. Sano M, Wilcock GK, Baelen B, et al. The effects of galantamine treatment on caregiver time in Alzheimer's disease. Int $\mathrm{J}$ Geriatr Psychiatry. 2003;18:942-50.

10. Suh GH, Jung HY, Lee CU, et al. Economic and clinical benefits of galantamine in the treatment of mild to moderate Alzheimer's disease in a Korean population: a 52-week prospective study. J Korean Med Sci. 2008;23:10-7.

11. Feldman H, Gauthier S, Hecker J, et al. Efficacy of donepezil on maintenance of activities of daily living in patients with moderate to severe Alzheimer's disease and effect on caregiver burden. J Am Geriatr Soc. 2003;51:737-44.

12. AD 2000 Collaborative Group. Long term donepezil treatment in 565 patients with Alzheimer's disease (AD randomised double-blind trial. Lancet. 2000;2004(363):2105-15.

13. Scheltens $\mathrm{P}$, Sperling $\mathrm{R}$, Salloway $\mathrm{S}$, Fox $\mathrm{N}$. Bapineuzumab IV phase 3 results. JNHA. 2014;16(9):797.

14. Zhu CW, Scarmeas N, Torgan R, et al. Clinical characteristics and longitudinal changes in informal cost of Alzheimer's disease in the community. JAGS. 2006;54:1596-602.

15. Mauskopf J, Racketa J, Sherrill E. Alzheimer disease: the strength of association of costs with different measures of disease severity. JNHA. 2010;14(8):655-63.

16. Rosen WG, Terry RD, Fuld PA, Katzman R, Peck A. Pathological verification of ischemic score in differentiation of dementias. Ann Neurol. 1980;7:486-8.

17. Wimo A, Winblad B. Resource utilization in dementia. Brain Aging. 2003;3:48-60.

18. Zhu CW, Leibman C, McLaughlin T, Scarmeas N, Albert M, Brandt J, Blacker D, Sano M, Stern Y. The effects of patient function and dependence on costs of care in Alzheimer's disease. J Am Geriatr Soc. 2008;56:1497-503.

19. Järbrink $\mathrm{K}$, McCrone $\mathrm{P}$, Fombonne $\mathrm{E}$, Zandén $\mathrm{H}$, Knapp M. Cost-impact of young adults with high-functioning autistic spectrum disorder. Res Dev Disabil. 2007;28(1):94-104.

20. Kernick DP, Reinhold DM, Netten A. What does it cost the patient to see the doctor? Br J Gen Pract. 2000;50(454):401-3 (3).

21. http://docs.nrdc.org/health/files/hea_08082601A. pdf. Accessed 8 May 2012.

22. Rosen WG, Mohs RC, Davis KL. A new rating scale for Alzheimer's disease. Am J Psychiatry. 1984;141:1356-64.

23. Folstein M, Folstein S, McHugh P. Mini-mental state: a practical method for grading the cognitive state of patients for the clinician. J Psychiat Res. 1975;12:189-98.

24. Gélinas I, Gauthier L, McIntyre M, Gauthier S. Development of a functional measure for persons with Alzheimer's disease: the disability assessment for dementia. Am J Occup Ther. 1999;53(5):471-81.

25. Cummings JL, Mega M, Gray $\mathrm{K}$, Rosenberg-Thompson S, Carusi DA, Gornbein J. The neuropsychiatric inventory: comprehensive assessment of psychopathology in dementia. Neurology. 1994;44(12):2308-14.

26. Stern Y, Albert SM, Sano M, Richards M, Miller L, Folstein M, Albert M, Bylsma FW, Lafleche G. Assessing patient dependence in Alzheimer's disease. J Gerontol. 1994;49:M216-22.

27. Clinical dementia rating scale. http://www.biostat. wustl.edu/ adrc/cdrpgm/index.html. Accessed 8 May 2012.

28. Brickman Brickman AM, Riba A, Bell K, Marder K, Albert M, Brandt J, Stern Y. Longitudinal assessment of patient dependence in Alzheimer disease. Arch Neurol. 2002;59:1304-8.

29. Zhu Leibman C, McLaughlin T, et al. The effects of patient function and dependence on cost of care in Alzheimer disease. J Am Geriatr Soc. 2008;56:1497-503. 